\title{
Struktur Komunitas Rumput Laut di Perairan Pasir Panjang Desa Olibuu Kabupaten Boalemo, Gorontalo
}

\author{
Edi Wibowo $^{1}$, Raden Ario ${ }^{1 *}$, Suryono ${ }^{1}$,Nur Taufiq SPJ $^{1}$, Destalino ${ }^{2}$ \\ ${ }^{1}$ Departemen Ilmu Kelautan, Fakultas Perikanan dan Ilmu Kelautan, Universitas Diponegoro \\ Jl. Prof. Sudarto, SH, Tembalang, Semarang, Jawa Tengah, 50275 \\ ${ }^{2}$ SMK Negeri 1 PaguyamanPantai \\ Jl. Kebun Sari, Bubaa, Kec. Paguyaman Pantai, Kab. Boalemo Prov. Gorontalo \\ Email: ario_1960@yahoo.com
}

\begin{abstract}
Abstrak
Rumput laut atau seaweed termasuk tumbuhan berthallus yang banyak dijumpai hampir di seluruh pantai Indonesia, terutama wilayah pantai yang mempunyai rataan terumbu karang. Perbedaan mendasar sistem hidupnya dengan tumbuhan darat adalah dalam pengambilan zat-zat makanan. Tumbuhan darat sangat bergantung pada akar sebagai alat pengambil/ penyerap zat hara dari substrat, sedangkan rumput laut menyerap zat hara yang dibutuhkan bagi pertumbuhannya dari medium air dengan cara difusi melalui permukaan substansi fisiknya.Penelitian ini bertujuan untuk mengetahui struktur komunitas rumput laut di perairan Pasir Panjang Pulau Limbah, Kecamatan Paguyaman Pantai, Kabupaten Boalemo, Provinsi Gorontalo. Metoda penelitian yang digunakan adalah bersifat diskriptif.Adapun pengumpulan data dilakukan dengan metode sample survey methods. Hasil penelitian menunjukkan bahwa perairan Pulau Limbah di dominasi oleh Rumput Laut Coklat dengan kelimpahan tertinggi Padina australis. Nilai Indeks Keanekaragaman (H') Rumput Laut tertinggi terdapat pada stasiun $\mathrm{C}$ dengan nilai rerata: 1,854 dan yang terendah pada Stasiun A dengan nilai rerata: 1,469. Nilai Indeks Keseragaman (E) nilai tertinggi terdapat pada Stasiun C dengan nilai rerata: 0,679 dan terendah pada stasiun A dengan nilai rerata: 0,668 . Nilai indeks Dominansi (C) tertinggi terdapat pada Stasiun A dengan nilai rerata : 0,251 dan nilai terendah stasiun B dengan nilai rerata: 0,187. Analisis Ragam (Anova) menunjukan bahwa stasiun penelitian memberikan perbedaan yang nyata $(\mathrm{P} \leq 0,05)$ terhadap nilai Indeks Keanekaragaman $\left(\mathrm{H}^{\prime}\right)$, Indeks Keseragaman $(\mathrm{E})$ serta Indeks Dominasi (C).
\end{abstract}

Kata Kunci: Rumput Laut, Keanekaragaman, Keseragaman, Dominansi

\section{Abstract \\ Community Structure of Seaweed In Perairan Pasir Panjang Village Olibuu Boalemo District, Gorontalo}

Seaweed including thallus plants that are found almost all over the coast of Indonesia, especially on beaches that have coral reefs. Seaweed is a photosynthetic organism as well as plants on land. The fundamental difference of his life system is in the taking of food substances. Ground plants realy heavily on roots as a nutrient removal device from the substrate, while seaweed absorbs the nutrients needed for its growth from the water medium by diffusion through the surface of its physical substance. This study aims to determine the structure of seaweed communities in Limbah Island Waters, District Paguyaman Beach. The results showed that the waters of Limbah Island is dominated by brown seaweed with the highest species abundance was Padina australis. The highest index value of Seaweed diversity $\left(H^{\prime}\right)$ was found at station $C$ with average: 1,854 and the lowest at station A with a mean of: 1,469. For uniformity index value (E) the highest value is at station $C$ with average: 0,679 and the lowest at station $A$ with a mean of: 0,668. The highest index value of dominance $(C)$ is at station $A$ with a mean of: 0,251 and the lowest value at station $B$ with a mean of: 0,187 . The result of the analysis of variance (Anova) showed that the research station give a significant difference $(P \leq 0,05)$ to the Diversity Index $\left(H^{\prime}\right)$, Uniformity Index $(E)$ and Domination Index $(C)$.

Keywords: Seaweed, Diversity, Uniformity, Dominance.

*Corresponding author

buloma.undip@gmail.com http://ejournal.undip.ac.id/index.php/buloma

Diterima/Received : 09-02-2018

Disetujui/Accepted : 23-03-2018 


\section{PENDAHULUAN}

Rumput laut merupakan organisme fotosintetik seperti juga halnya tumbuhan di darat. Menurut Hafting et.al. (2012) dan Destalino (2013), secara umum rumput laut digolongkan menjadi 3 (tiga) kelas besar dari Divisi Thalophyta, yaitu : Rhodophyceae, Chlorophyceae, dan Phaeophyceae. Rumput laut menyerap zat hara yang dibutuhkan bagi pertumbuhannya dari medium air dengan cara difusi melalui permukaan tubuh fisiknya. Pertumbuhan rumput laut ini sangat bergantung pada kualitas air serta faktor-faktor oseanografis dan tersedianya substrat dasar sebagai habitatnya (Mouritsen, 2013). Struktur komunitas rumput laut suatu perairan sangat dipengaruhi oleh subtrat dasar serta parameter kualitas air terutama suhu dan arus (Campbellet.al). 2008). Rumput laut yang hidup pada perairanberarus kuat akan mempunyai karakteristik yang berbeda dengan rumput laut yang hidup pada perairan yang berarus pelan (Neish, 2003). Penelitian ini bertujuan untuk mengetahui struktur komunitas rumput laut di perairan pantai Pasir Panjang Pulau Limbah, Kecamatan Paguyaman Pantai, Kabupaten Boalemo, Provinsi Gorontalo.Muara sungai Demaan Desa Olibuu, Kabupaten Boalemo dipilih sebagai lokasi penelitian dengan pertimbangan kawasan tersebut merupakan perairan estuaria yang diduga mengalami penurunan kualitas perairan akibat aktivitas manusia di lingkungan sekitarnya.Stasiun yang digunakan dalam penelitian ini adalah perairan muara sungai yang berhadapan dengan Teluk Tomini.

Bentuk thalus rumput laut bermacammacam, antara lain bundar seperti tabung, pipih, gepeng, seperti kantong, dan seperti rambut. Thalus ada yang tersusun satu sel (uniseluler)atau banyak sel (multiseluler). Percabangan thalus ada yang bercabang dua terus-menerus (dichotomous), berderet searah pada satu sisi thalus utama(pectinate), bercabang dua-dua pada sepanjang thalus utama berselang-seling (pinnate),cabang berpusat melingkari aksis atau sumbu utama (ferticilate), dan tidak bercabang (Campbell et.al., 2008). Sementara menurut Aslan (2008) bahwa sifat substansi thalus juga beragam, ada yang lunak seperti gelatin (gelatinous), keras atau mengandung kapur (calcareous), lunak seperti tulang rawan (cartilagenous), dan berserabut (spongius).Sebagian besar tumbuhan yang hidup sebagai algae terdiri dari algae bentik dan algae planktonik (Mouritsen, 2013). Cara hidupnya bisa sebagai fitoplankton yang mengapung atau melayang di dalam air dan bisa pula sebagai fitobentos yang hidup menancap atau melekat di dasar laut. Hutan kelp merupakan kawasan rumput laut yang luas membentuk hutan didalam perairan laut. Kawasan hutan kelp memberikan struktur fisik yang mendukung kehidupan organism laut dengan menyediakan makanan dan tempat berlindung (Campbell et.al.,2008). Hutan kelp bertindak sebagai kawasan pembibitan bawah air untuk banyak hewan laut, seperti ikan, gastropoda, dan bivalvia. Hutan kelp yang subur membentuk kanopi hutan lebat diperairan lautdimana invertebrata, kepiting, cacing, dan ikan laut dapat menemukan habitatnya dengan banyak makanan.

\section{MATERI DAN METODE}

Metode penelitian yang digunakan adalah bersifat deskriptif. Menurut Sudjana (1992) bahwa penelitian deskriptif merupakan penelitian mengenai situasi atau kejadian yang diteliti pada waktu dan tempat tertentu untuk mendapat gambaran tentang situasi dan kondisi yang bersifat lokal. Adapun pengumpulan data dilakukan dengan sample survey methods (Hadi, 1984). Metode ini dilakukan dengan mengambil sebagian kecil populasi yang dapat menggambarkan sifat populasi dari obyek penelitian. Penelitian ini dilaksanakan pad atanggal 27 Juli 2017 di perairan pantai Pasir Panjang Pulau Limbah, Kecamatan Paguyaman Pantai, Kabupaten Boalemo, Provinsi Gorontalo.

Penelitian dilakukan dalam dua tahap, yaitu (1) penelitian pendahuluan dan (2) penelitian lapangan. Menurut Sudjana (1992)penelitian pendahuluan bertujuan untuk menentukan lokasi penelitian yaitu dengan menggunakan metode sampling pertimbangan (purposive sampling methods).Penelitian dilakukan di3 stasiun A, B, dan $\mathrm{C}$ dengan setiap stasiunnya dibagi jadi 4 substasiun yang merupakan jarak perairan dari daratan yaitu: $25 \mathrm{~m}, 50 \mathrm{~m}, 75 \mathrm{~m}$ dan $100 \mathrm{~m}$.

Data berupa keanekaragaman jenis yang dianalisa menggunakan Indeks Keanekaragaman jenis Shanon-Weaver (Odum, 1993).

$$
H^{\prime}=-\sum_{i=1}^{n} \frac{n i}{N} \operatorname{Ln} \frac{n i}{N}
$$

dengan :

$\mathrm{H}^{\prime}=$ Indeks keanekaragamanjenis

ni $=$ Jumlah individu ke- $\mathrm{i}$

$\mathrm{N}=$ Jumlah total individu seluruh jenis

Interpretasi :

$\mathrm{H}^{\prime}<1=$ berarti komunitas dalam keadan tak stabil 

$1<\mathrm{H}^{\prime}<3=$ berarti komunitas dalam kondisi sedang (moderat)

$\mathrm{H}^{\prime}>3$ = berarti komunitas dalam kondisi baik

Indeks keseragaman dihitung menggunakan rumus dari Odum (1993) yaitu :

$$
\mathrm{E}=\frac{\mathrm{H}^{\prime}}{\ln \mathrm{S}}
$$

dengan:

$\mathrm{E}=$ indeks keseragaman

$\mathrm{H}^{\prime}$ = indeks keanekaragaman

$\mathrm{S} \quad=$ jumlah macam spesies

Interpretasi : Bila nilaiE mendekati 0 (nol), spesies penyusunnya tidak banyak ragamnya, ada dominasi dari spesies tertentu dan menunjukkan adanya tekanan terhadap ekosistem. Bila E mendekati 1 (satu), jumlah individu yang dimiliki antar spesies tidak jauh berbeda, tidak ada dominasi dan tidak ada tekanan terhadap ekosistem.Indeks Dominasi (C) dihitung dengan menggunakan rumus (Odum 1993):

$$
\mathrm{C}=\sum_{1=1}^{n}\left(\frac{n i}{N}\right)^{2}
$$

dengan :

$\mathrm{C}=$ Indeks Dominansi Simpson

ni = Jumlah individu jenis ke-i

$\mathrm{N}=$ Jumlah total individu seluruhjenis

Interpretasi : Bila nilai C mendekati 0 (nol), didalam komunitas tersebut tidak ada spesies yang dominan, komunitas dalam keadaan stabil, dan bila nilai C mendekati 1 (satu), ada dominasi dari spesies tertentu, komunitas berada dalam keadaan labil dan terjadi tekanan pada ekosistem.

\section{HASIL DAN PEMBAHASAN}

\section{Pengamatan Kelimpahan Rumput Laut}

Kelimpahan rumput laut pada stasiun A didominasi oleh Alga coklat (Phaeophyceae) sebanyak 9 spesies, dengan kelimpahan rumpun yang paling banyak adalah Padina australis sebanyak 6individu. Kelimpahan rumput laut pada stasiun B di dominasi oleh Alga coklat sebanyak 7 spesies, dengan kelimpahan yang paling banyak adalah Sargassum crasifolium sebanyak6 individu. Kelimpahan rumput laut pada stasiun $\mathrm{C}$ di dominasi oleh Alga coklat sebanyak 7 spesies, dengan kelimpahan yang paling banyak adalah Sargassum crasifolium sebanyak 8 individu. Data sampel rumput laut dapat dilihat pada Tabel 1.

\section{Indeks Keanekaragaman ( $\left.\mathrm{H}^{\prime}\right)$}

Tabel 2 menyajikan hasil nilai rerata pengamatan rumput laut di Perairan Pantai Pasir Panjang Desa Olibuu yang nilai Indeks Keanekaragaman (H') menunjukan bahwa Stasiun A memiliki nilai Indeks Keragaman berkisar antara 1,099-1,748 dengan rerata: 1,469 . Sedangkan di Stasiun B berkisar 1,342 - 2,023 dengan rerata : 1,774 dan Stasiun C berkisar 1,427 - 2,195 dengan rerata: 1,854 .

Tabel 3 menyajikan hasil analisis ragam pada stasiun penelitian tersebut memberikan pengaruh yangberbeda nyata $(\mathrm{P} \leq 0.05)$ terhadap Indeks Keanekaragaman (H').

\section{Indeks Keseragaman $(E)$}

Gambar 1 menyajikan hasil pengamatan rumput laut dengan nilai IndeksKeseragaman (E) pada Stasiun A berkisar antara 0,632 - 0,693 dengan rerata : 0,668 , sedangkan di Stasiun B berkisar 0,665 - 0,674 dengan rerata: 0,670, dan Stasiun C berkisar 0,615 - 0,782 dengan rerata : 0,679 . Tabel 4 menyajikan hasil analisa ragam menunjukan bahwa Stasiun penelitian memberikan pengaruh yang berbeda nyata $(\mathrm{P} \leq 0.05)$ terhadap Indeks Keseragaman (E).

\section{Indeks Dominansi $(C)$}

Hasil pengamatan pada Gambar 2 menunjukan nilai Indeks Dominansi rumput laut pada Stasiun A berkisar antara 0,184 - 0,333 dengan rerata : 0,251.Sedangkan di Stasiun B berkisar 0,139-0,280 dengan rerata : 0,187, dan Stasiun C berkisar 0,139-0,315 dengan rerata : 0,233 . Berikut Gambar 2 yaitu: Grafik nilai Indeks Dominansi rumput laut.

Hasil Analisis Ragam menunjukan bahwa Stasiun penelitian memberikan pengaruh yang berbeda nyata $(\mathrm{P} \leq 0.05)$ terhadap Indeks Dominansi (C). Gambar 3 menunjukan nilai Regresi Jarak Sampling dari pantai (sub stasiun) terhadap nilai Indeks Keanekaragaman (H'), Indeks Keseragaman (E), dan Indeks Dominansi(C).

Terlihat pada Gambar 3 bahwa Jarak Sampling dari pantai mempunyai hubungan korelasi yang positif dengan nilai Indeks Keanekaragaman, dengan nilai koefisien korelasi (R) sebesar 0,504. Gambar 4 dapat terlihat bahwa Jarak Sampling dari pantai mempunyai hubungan korelasi yang positif dengan nilai Indeks Keseragaman, dengan nilai koefisien korelasi (R) sebesar 0,012 .

Terlihat pada Gambar 5 bahwa Jarak sampling dari pantai mempunyai hubungan 
korelasi yang negatif dengan nilai Indeks Dominansi, dengan nilai koefisien korelasi (R) sebesar 0,331.Parameter lingkungan yang diukur dalam penelitian ini meliputi salinitas, suhu, derajat keasaman $(\mathrm{pH})$, kedalaman, kecepatan arus, dan substrat dasar. (Tabel 5).

Tabel 1. Kelimpahan Rumput Laut pada stasiun penelitian

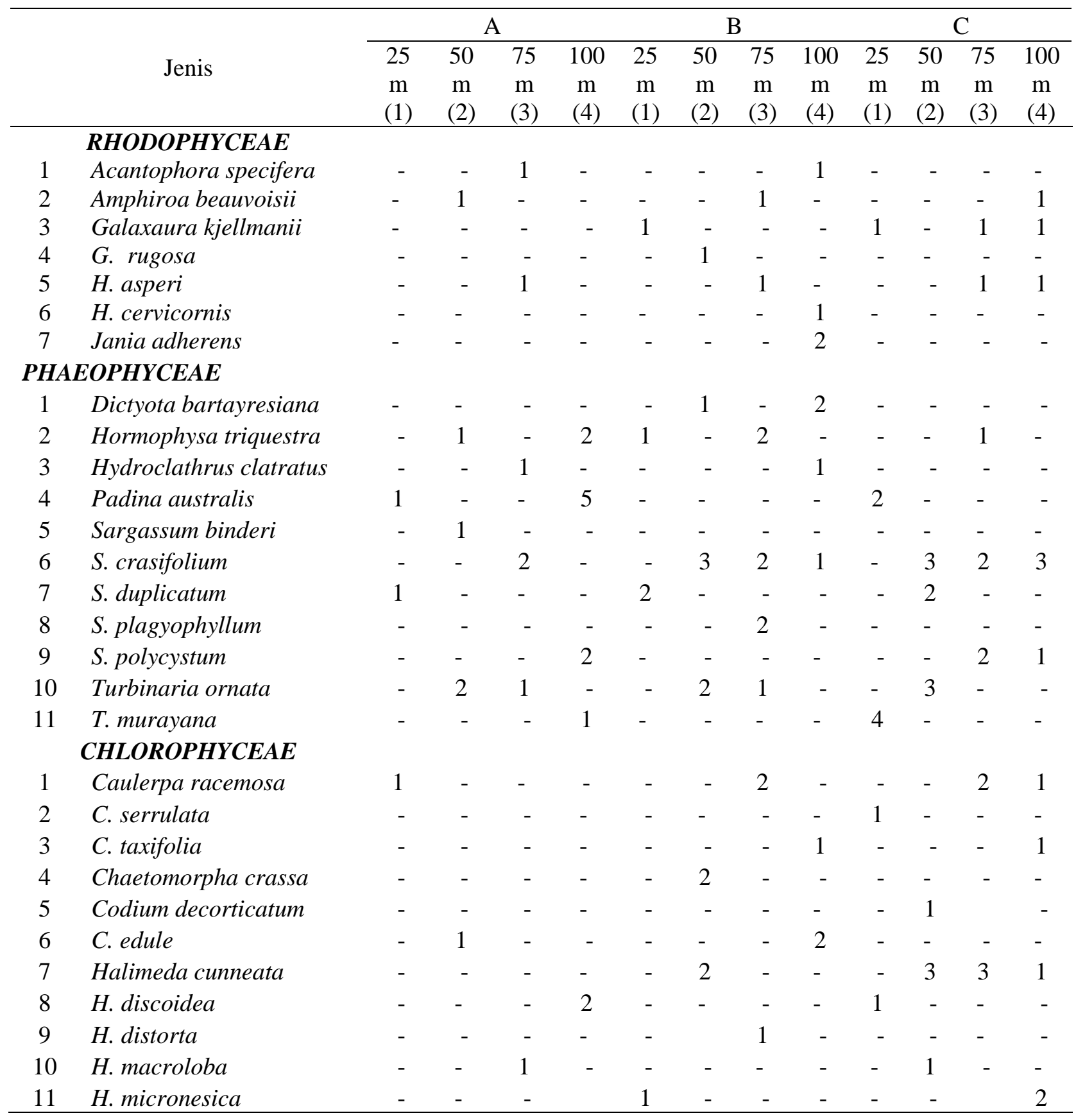

Tabel 2. Nilai Rerata Indeks Keanekaragaman (H'), Keseragaman (E) dan Dominasi (C) tiap stasiun

\begin{tabular}{cccc}
\hline \multirow{2}{*}{ Stasiun } & \multicolumn{3}{c}{ Indeks } \\
\cline { 2 - 4 } & $\mathrm{H}^{\prime}$ & $\mathrm{E}$ & $\mathrm{C}$ \\
\hline $\mathrm{A}$ & 1.469 & 0.668 & 0.251 \\
$\mathrm{~B}$ & 1.774 & 0.670 & 0.187 \\
$\mathrm{C}$ & 1.854 & 0.679 & 0.233 \\
\hline
\end{tabular}


Tabel 3. Hasil Analisis Ragam Indeks Keanekaragaman (H')

\begin{tabular}{lrcrrrr}
\hline Sumber variasi & Jumlah kuadrat & Derajat bebas & Kuadrat rerata & $\mathrm{F}_{\text {hitung }}$ & Nilai Probability & $\mathrm{F}_{\text {kritis }}$ \\
\hline Antar kelompok & 0.330 & 2 & 0.165 & 1.606 & $\left.0.253^{*}\right)$ & 4.256 \\
Dalam kelompok & 0.924 & 9 & 0.102 & & & \\
Total & 1.254 & 11 & & & & \\
\hline
\end{tabular}

Keterangan: ${ }^{*}$ berbeda nyata

Tabel 4. Hasil Analisis Ragam Indeks Keseragaman (E).

\begin{tabular}{lrrrrrr}
\hline Sumber variasi & Jumlah kuadrat & Derajat bebas & Kuadrat rerata & $\mathrm{F}_{\text {hitung }}$ & Nilai Probabiliti & $\mathrm{F}_{\text {kritis }}$ \\
\hline Antar Kelompok & 0.00024 & 2 & 0.00012 & 0.06154 & $0.94071^{*}$ & 4.2565 \\
Dalam Kelompok & 0.01762 & 9 & 0.00196 & & & \\
Total & 0.01787 & 11 & & & & \\
\hline
\end{tabular}

Keterangan: ${ }^{*}$ berbeda nyata

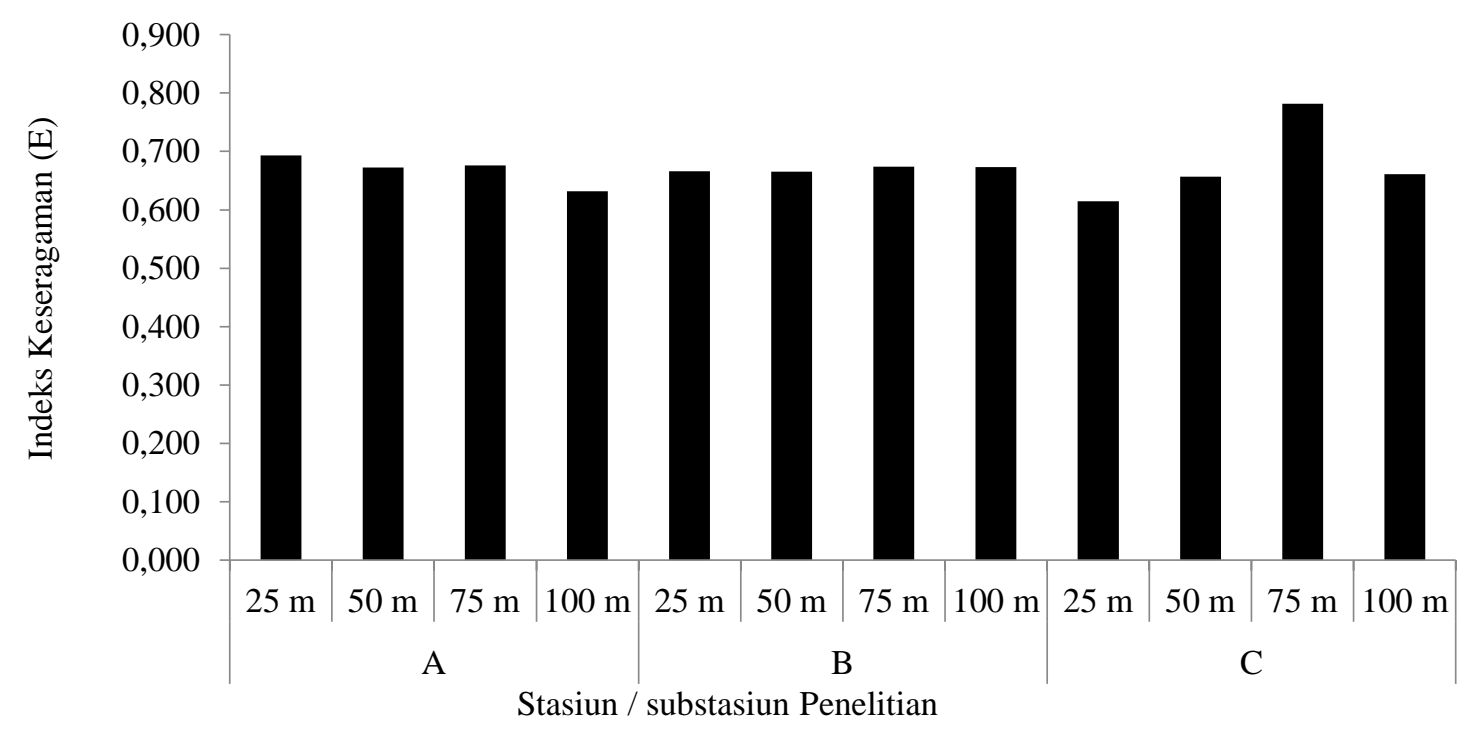

Gambar 1. Indeks Keseragaman rumput laut di Perairan Pantai Pasir Panjang.

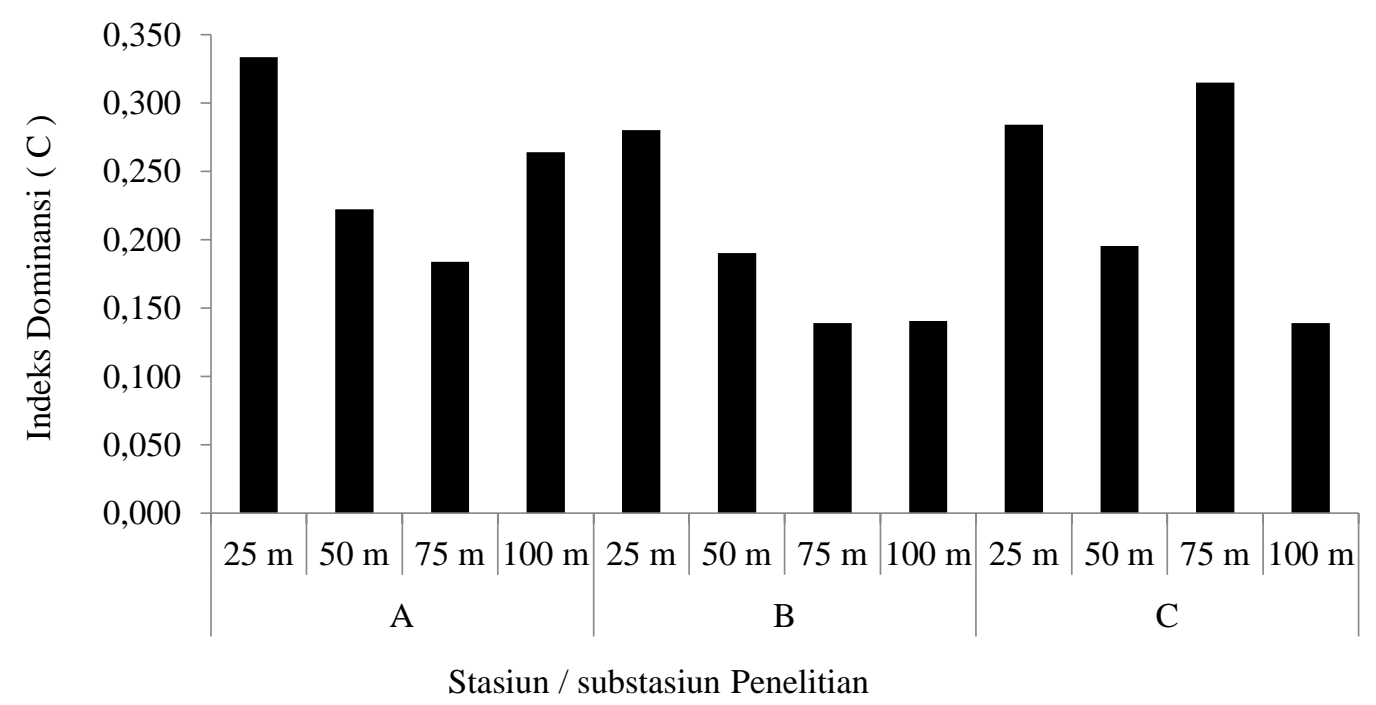

Gambar 2. Indeks Dominansi Rumput Laut di Perairan Pantai Pasir Panjang Desa Olibuu 


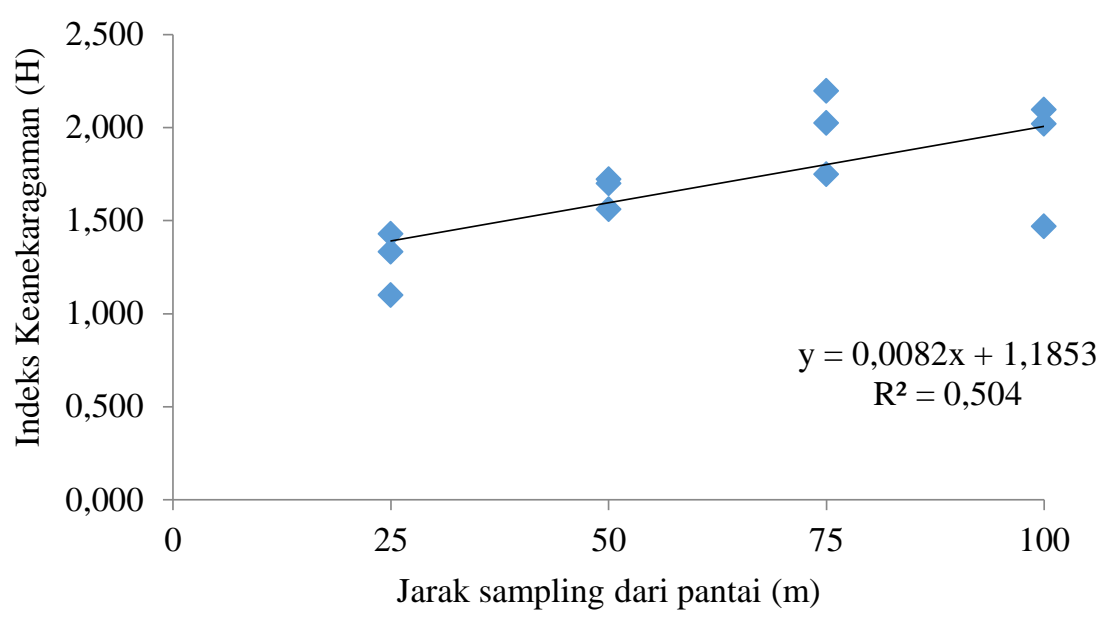

Gambar 3. Regresi Indeks Keanekaragaman Rumput Laut di Perairan Pasir Panjang Desa Olibuu

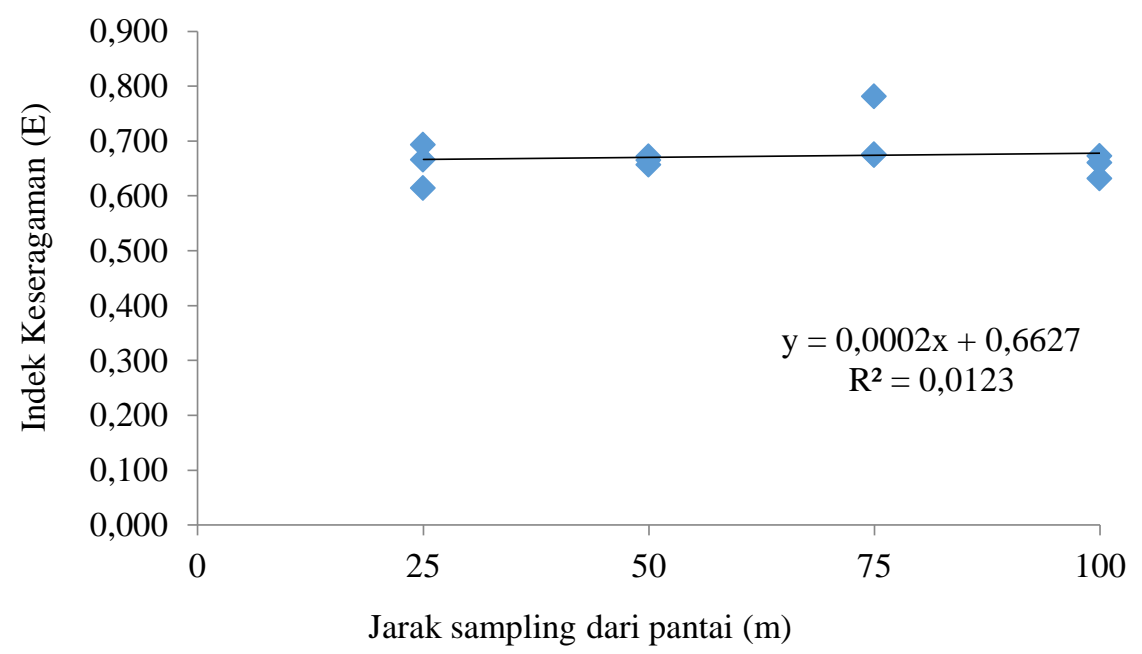

Gambar 4. Regresi Indeks Keseragaman Rumput Laut di Perairan Pasir Panjang Desa Olibuu

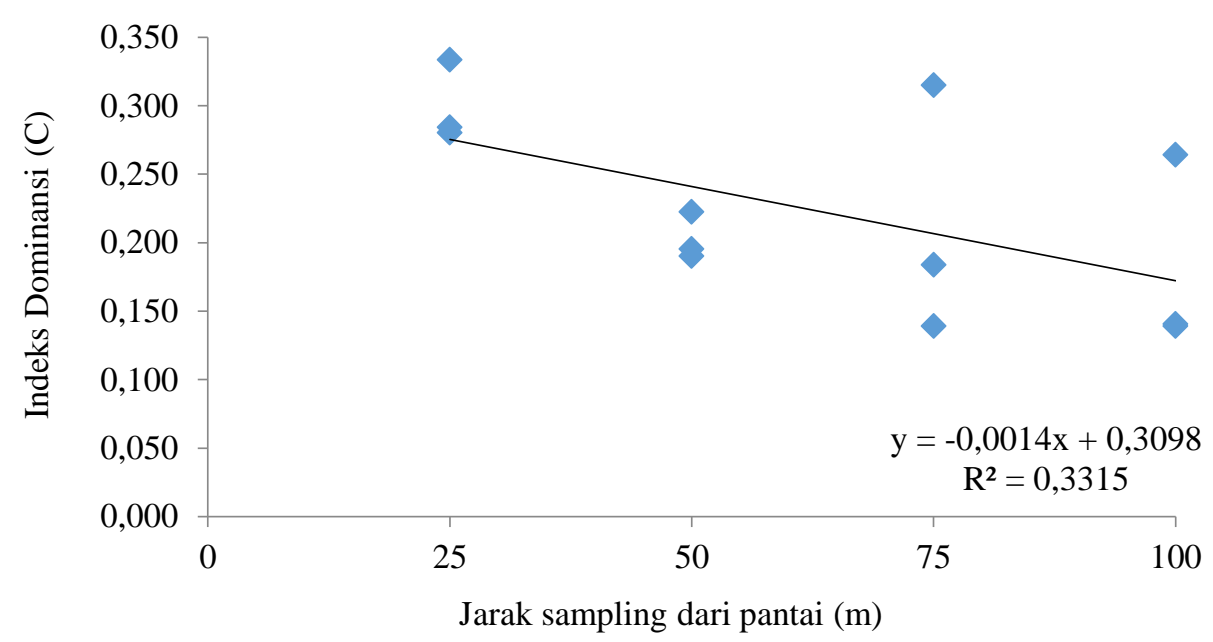

Gambar 5. Regresi Indeks Dominansi Rumput Laut di Perairan Pasir Panjang Desa Olibuu 
Tabel 5. Nilai Rerata Kualitas Air yang terukur pada perairan Pasir Panjang Desa Olibuu.

\begin{tabular}{lccc}
\hline \multirow{2}{*}{ Parameter } & \multicolumn{3}{c}{ Stasiun } \\
\cline { 2 - 4 } & $\mathrm{A}$ & $\mathrm{B}$ & $\mathrm{C}$ \\
\hline Salinitas $(\mathrm{ppt})$ & $32-35$ & $31-34$ & $32-34$ \\
Suhu $\left({ }^{0} \mathrm{C}\right)$ & $28-30$ & $31-32$ & $31-32$ \\
$\mathrm{pH}$ & $7,8-8,2$ & $8,1-8,4$ & $7,9-8,5$ \\
Kedalaman $(\mathrm{m})$ & 1,35 & 1,04 & 1,42 \\
Kecepatan arus (cm/det) & $5,7-7,4$ & $5,8-6,2$ & $6,7-8,1$ \\
Subtrat & Pasir berbatu & Pecahan karang & Pasir berbatu \\
\hline
\end{tabular}

Nilai rerata Indeks Keanekaragaman tertinggi terdapat pada Stasiun C dengan nilai 1,854 , sedangkan nilai Indeks Keanekaragaman terendah terdapat pada stasiun A sebesar 1,469. Secara umum Indeks Keanekaragaman pada Perairan Pasir Panjang Desa Olibuu termasuk dalam kategori sedang, sesuai dengan nilai indeks Shannon Weaver yang menyatakan bahwa nilai Indeks Keanekaragaman 1-3 termasuk dalam kategori sedang. Selanjutnya lebih lanjut dikatakan Odum (1998) bahwa suhu rerata air laut berkisar antara $28-32^{\circ} \mathrm{C}$ dan di perairan yang dangkal dapat di jumpai suhu yang lebih tinggi lagi, kadangkadang sampai $35^{\circ}$ C. Lebih lanjut dikatakan bahwa semakin besar nilai Indeks Keanekaragaman berarti semakin banyak jenis yang di dapat, nilai Indeks Keanekaragaman sangat bergantung pada kelimpahan total individu masing-masing jenis. Hasil AnalisisRagam(Anova) memberikan hasil yang yang berbeda terhadap nilai Indeks Keanekaragaman antar stasiun pada perairan Pasir Panjang Desa Olibu. Dinyatakan Wibisono (2008) bahwa nilai Indeks Keanekaragaman sangat dipengaruhi oleh faktor internal seperti persaingan diantara spesies dalam memanfaatkan ruang maupun makanan serta faktor eksternal yang menyebabkan lingkungan terganggu seperti terjadinya pencemaran air, adanya eksploitasi sumberdaya perikanan atau produktivitas biologis yang rendah.

Nilai rerata Indeks Keseragaman tertinggi pada Perairan Pasir Panjang Desa Olibuu terdapat pada Stasiun C sebesar 0,679, dan yang terendah pada Stasiun A sebesar 0,668. Secara umum nilai Indeks Keseragaman pada Perairan Pasir Panjang Desa Olibuu termasuk kategori tinggi, yaitu mendekati 1 ( $\geq 0.6$ ). Menurut Pielou (1969) dalam Romimohtarto dan Juwana (1999), nilai Indeks Keseragaman $\geq 0,6$ menggambarkan keseimbangan populasi yang besar. Sementara itu Odum (1993) menyatakan bahwa nilai Indeks Keseragaman menunjukan tingkat penyebaran individu tiap spesies, sehingga dengan nilai Indeks
Keseragaman yang didapat dalam penelitian ini dapat dikatakan bahwa penyebaran populasi rumput laut di Perairan Pasir Panjang Desa Olibuu merata. Lebih lanjut dikatakan bahwa nilai Indeks Keseragaman semakin kecil, maka penyebaran jumlah individu tiap spesies tidak sama, ada suatu kecenderungan bahwa komunitas didominasi olehspesies tertentu. Hasil AnalisisRagam(Anova) terhadap Indeks Keseragaman memberikan hasil yang berbeda nyata antar stasiun pada Perairan Pasir Panjang Desa Olibuu. Wilhm and Dorris (1968) dalam Odum (1998) menyatakan bahwa apabila jumlah individu masing-masing jenis cukup berimbang, maka akan di jumpai nilai Indeks Keseragaman yang tinggi $(>0,7)$. Kemampuan suatu individu untuk bertahan hidup pada suatu kondisi tidaklah sama. Destalino (2013) menyatakan bahwa fungsi ekosistem optimum, suatu perairan dengan salinitas $30-35$ ppt akan sangat mendukung pertumbuhan dan perkembangan rumput laut. Lebih lanjut Mouritsen (2013) menyatakan bahwa salinitas air laut sangat berpengaruh terhadap pertumbuhan rumput laut. Beberapa jenis rumput laut mengalami penurunan ukuran thalus dengan bertambahnya salinitas. Demikian juga, penurunan salinitas dapat menyebabkan perubahan morfologi dan fisiologi jenis rumput laut tertentu, misalnya seperti Caulerpa sp., Porphyra sp., dan Eucheuma $s p$.Tidak semua perairan laut mempunyai nilai salinitas yang sama. Nilai salinitas yang cocok untuk lokasi budi daya rumput laut jenis Eucheuma $s p$. berkisar antara 28-32 ppt, sedangkan untuk jenis Gracilaria sp. berkisar antara 15-25 ppt.

Nilai rerata Indeks Dominasi pada Perairan Pasir Panjang Desa Olibuu tertinggi terdapat pada Stasiun A sebesar 0,251 dan yang mempunyai nilai terendah Stasiun B sebesar 0,187. Nilai Indeks Dominasi yang di dapat dalam penelitian ini lebih rendah dari 0,5 , hal ini berarti tidak ada individu yang mendominasi dalam populasi (Odum, 1998).

Sementara itu Scrosati (2006) menyatakan bahwa terdapatnya suatu individu yang 
mendominasi suatu populasi jika mempunayai Indeks Dominasi > 0,6. Hasil Analisis Ragam (Anova) terhadap nilai Indeks Dominasi memberikan hasil yang berbeda nyata antar stasiun pada Perairan Pasir Panjang Desa Olibuu. Dominasi suatu organisme juga sangat di pengaruhi oleh kualitas perairan, seperti suhu perairan. Sedangkan dalam Scrosati (2006) dinyatakanbahwa beberapa Alga yang hidupnya tergantung pada suhu perairan, misalnya Alga biruhijau hidup pada suhu $45^{\circ} \mathrm{C}$ sedangkan Alga hijau 30-33 $3^{\circ}$ C. Dinyatakan dalam Mouritsen (2013) bahwa secara umum rumput laut dapat hidup dan tumbuh normal pada kisaran suhu 28-32 ${ }^{\circ} \mathrm{C}$. Pemanasan perairan akan berpengaruh terhadap perkembangan stadia reproduksi beberapa jenis rumput laut, misalnya perkembangan tetraspora Polysiphonia sp.akan berlangsung baik pada suhu antara 25-30 ${ }^{\circ} \mathrm{C}$. Rumput laut dari Filum Chlorophyceae (Alga hijau) tumbuh baik pada kisaran suhu $30-35{ }^{\circ} \mathrm{C}$. Sementara, filum Cyanophyceae (Alga biru) dapat bertoleransi pada suhu yang lebih tinggi.

Disamping itu nilai $\mathrm{pH}$ suatu perairan juga akan berpengaruh terhadap penyebaran organisme perairan. Nilai $\mathrm{pH}$ zat cair menunjukan aktivitas ion hidrogen dalam perairan. Kondisi $\mathrm{pH}$ tinggi (basa) persentase amonia yang tidak terionisasi dalam larutan akan semakin besar, tapi sebaliknya persentase $\mathrm{H}_{2} \mathrm{~S}$ yang tidak terionisasi akan semakin kecil. Lebih lanjut nilai $\mathrm{pH}$ akan naik pada siang hari dan turun pada malam hari. Kisaran nilai $\mathrm{pH}$ saat penelitian ini berkisar antara 7,8-8,5, kisaran ini masih dalam kisaran yang layak untuk $\mathrm{pH}$ perairan laut berkisar antara 5,6-8,5.

\section{KESIMPULAN}

Hasil penelitian ini dapat disimpulkan bahwa pada daerahPerairan Pasir Panjang Desa Olibuu di dominasi oleh Alga coklat.Secara struktur komunitas Perairan Pasir Panjang Desa Olibuu dapat dikategorikan kondisi sedang (moderat). Tidak terdapat jenis atau spesies Rumput Laut yang dominan di Perairan Pasir Panjang Desa Olibuu. Secara umum parameter kualitas perairan cukup mendukung untuk pertumbuhan dan perkembangan Rumput Laut.

\section{DAFTAR PUSTAKA}

Aslan. L.M. 2008. Budidaya Rumput Laut. Penerbit Kanisius. Yogjakarta. 97 Hal.

Campbell, N.A., Reece, J.B.\& Urry, L.A. 2008. Biology, Eighth Edition. San Francisco, Pearson Benjamin Cummings.
Choi, T.S., Kang, E.J., Kim, J.H. \& Kim, K.Y., 2010.Effect of salinity on growth and nutrient uptake of Ulva pertusa (Chlorophyta) from an eelgrass bed. Algae, 25(1):17-26. DOI : 10.44 90/algae.2010.25.1.017

Dhargalkar, V.K. 2004. Seaweeds: A field manual. National Institute of Oceanography. New Delhi.

Destalino. 2013. Budidaya Rumput Laut. Faktor Ekologi Yang Mempengaruhi Keberhasilan Budidaya. Penerbit Kanisius. Yogjakarta. 144 hal

Haas, A.F., Smith, J.E., Thompson, M. \&Deheyn, D.D., 2014.Effects of reduced dissolved oxygen concentrations on physiology and fluorescence of hermatypic corals and benthic algae. Peer J. 2(235):1-19. DOI : 10.7717/ peerj. 235

Hafting, J.T., Critchley, A.T., Cornish, M.L., Hubley, S.A. \& Archibald, A.F., 2012. Onland cultivation of functional seaweed products for human usage. J. App. Phycol. 24(3):385-392. DOI :10.1007/s10811011-9720-1

Harley, C.D., Anderson, K.M., Demes, K.W., Jorve, J.P., Kordas, R.L., Coyle, T.A. \& Graham, M.H., 2012. Effects of climate change on global seaweed communities. $J$. Phycology, 48(5):1064-1078. DOI : 10.1111/j. 15298817.2012.01224.x

Kadi, A. 2005.Makro Algae di Perairan Kepulauan Bangka Belitung dan Karimata.Ilmu Kelautan. 10(2):98-105.

Mouritsen, O.G. 2013. Seaweeds: edible, available, and sustainable. University of Chicago Press.

Neish, I.C. 2003.The ABC of Eucheuma seaplant production. Argonomy, biology and crophandling of Betaphycus, Eucheuma and Kappaphycus the gelatinae, spinosum and cottonii of commerce.SEAPlant.net Monograph HB2F, 1008, p.V3.

Odum, E.P. 1998. Fundamental of Ecology. W. B. Sounders Company. Philadelphia. 574 hal.

Scrosati, R., 2001. Population dynamics of Caulerpa sertularioides (Chlorophyta: Bryopsidales) from Baja California, Mexico, during El Niño and La Niña years. J. Mar. Biol. Assoc. United Kingdom, 81(5):721-726.

Sudjana. 1992. Metode Statistika. Penerbit Tarsito. Bandung. 508 hal.

Wibisono, M.S. 2008. Pengantar Ilmu Kelautan. Grasindo. Jakarta. 226 Hal. 